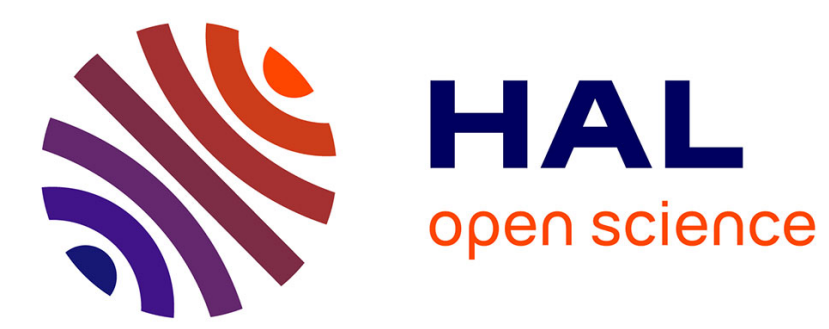

\title{
COMPARISON OF SITE OCCUPATION DETERMINATIONS BY APFIM AND AEM
}

\author{
M. Miller, J. Bentley
}

\section{To cite this version:}

M. Miller, J. Bentley. COMPARISON OF SITE OCCUPATION DETERMINATIONS

BY APFIM AND AEM. Journal de Physique Colloques, 1986, 47 (C7), pp.C7-463-C7-468. 10.1051/jphyscol:1986778 . jpa-00225973

\section{HAL Id: jpa-00225973 https://hal.science/jpa-00225973}

Submitted on 1 Jan 1986

HAL is a multi-disciplinary open access archive for the deposit and dissemination of scientific research documents, whether they are published or not. The documents may come from teaching and research institutions in France or abroad, or from public or private research centers.
L'archive ouverte pluridisciplinaire HAL, est destinée au dépôt et à la diffusion de documents scientifiques de niveau recherche, publiés ou non, émanant des établissements d'enseignement et de recherche français ou étrangers, des laboratoires publics ou privés. 


\title{
COMPARISON OF SITE OCCUPATION DETERMINATIONS BY APFIM AND AEM
}

\author{
M.K. MILLER and J. BENTLEY \\ Metals and Ceramics Division, Oak Ridge National Laboratory, \\ Oak Ridge, TN 37831, U.S.A.
}

\begin{abstract}
A comparison of the site occupation of a substitutional element determined from atom probe field-ion microscopy and from zone axis electron channeling microanalysis in the analytical electron microscope is presented. These techniques permit the site occupation for multiple elements to be determined in polycrystalline specimens. The material used in these experiments was an L12 ordered $\left(\mathrm{A}_{3} \mathrm{~B}\right) \mathrm{Ni}-24$ at.\% Al - 0.24 at.\% B series of alloys containing additions of hafnium, cobalt, or iron. The results of these two techniques indicated that, for the particular alloy compositions studied, hafnium has a strong preference for the aluminum sites, cobalt has a strong preference for the nickel sites, and iron has a weak preference for the aluminum sites. These results are in agreement with the site preference suggested from the direction of the solubility lobes in experimentally determined ternary phase diagrams.
\end{abstract}

\section{INTRODUCTION}

The location of an alloying addition in an ordered lattice is an important parameter in alloy development. The site location of these additions can be determined by either atom probe field-ion microscopy (APFIM) [1] or in the analytical electron microscope (AEM) by zone axis electron channeling microanalysis [2], which is an extension of the ALCHEMI method [3]. Both these techniques have the advantage that polycrystalline specimens can be used and since the ordered matrix can be selected for analysis they are not affected by any other phases that might be present in the microstructure. This is in contrast to the single crystal specimens required by the more conventional $x$-ray diffraction and ion channeling techniques. The APFIM and AEM techniques are also capable of quantifying the site occupation for multiple elements simultaneously. The techniques require no special equipment or modifications to existing instruments. The atom probe has the additional advantage of being able to examine materials that are far from the stoichiometric composition.

In this paper a comparison of the site preference of substitutional elements measured by these two techniques is presented. A series of nickel aluminides was selected for the comparison since many different elements are soluble in the L1/2 ordered $\mathrm{Ni}_{3} \mathrm{Al}$ phase and the degree of long range order exhibited by this phase is high. Several substitutional elements have been added to the $\mathrm{Ni} 3 \mathrm{Al}$ system to refine its good properties for high temperature applications [4]. Three substitutional additions were selected for this controlled study because of their anticipated different site preference.

\section{EXPERIMENTAL}

The compositions of the alloys chosen for this investigation are summarized in Table 1. The alloys were based on a composition of $\mathrm{NI}-24.0$ at.\% Al -0.24 at.\% B with additions of hafnium, cobalt and iron. The aluminum and nickel levels in the alloys were adjusted assuming that the substitutional element additions would prefer a 
specific site in the ordered lattice. The alloys were all within the solubility limits of the $\mathrm{L}_{2}$ phase field in their respective ternary phase diagrams.

Table 1. Nominal Compositions of Alloys ( atomic \%).

\begin{tabular}{|c|c|c|c|}
\hline Substitutional Element & Al & Ni & B \\
\hline $0.5 \%$ Hf & 23.4 & 75.9 & 0.24 \\
$1 \%$ Hf & 22.9 & 75.8 & 0.24 \\
$3 \%$ Hf & $20: 9$ & $75: 8$ & 0.24 \\
$6 \%$ Co & 23.9 & $69: 8$ & 0.24 \\
$6 \%$ Fe & $20: 9$ & 72.8 & 0.24 \\
\hline
\end{tabular}

The APFIM analyses were conducted on the ORNL energy-compensated atom probe [5]. The electron channeling microanalysis was performed on Philips EM40OT/FEG and EM430T analytical electron microscopes equipped with EDAX 9100/70 EDS systems.

\section{ATOM PROBE MICROANALYSIS}

The site occupation of a substitutional element is calculated in the atom probe from the preference of that element between the different atomic layers in the ordered structure. The optimum planes to analyze are those with the largest composition difference in successive layers, ideally pure $A$ versus pure $B$, and which have the maximum planar density of atoms. Unfortunately the $\mathrm{L}_{2}$ ( $\mathrm{A}_{3} \mathrm{~B}$ ) structure does not exhibit any planes with an A:B stacking sequence. The 001 planes, which alternate between pure $A$, and mixed $A+B$, fulfill the above criteria in the $L_{2}$ structure and $^{2}$ were therefore used for all analyses.

The position of the probe aperture must be carefully chosen to prevent artifacts. Three possible positions are shown schematically in figure 1. The position of the probe aperture is chosen to ensure that all atoms from the first layer are collected before any atoms are collected from the next plane. Position $X$ fulfills these requirements. Position $Y$ is not suitable as two planes will be sampled simultaneously. Position $z$ should not be used because of the trajectory aberrations that have been observed at the center of poles [6].
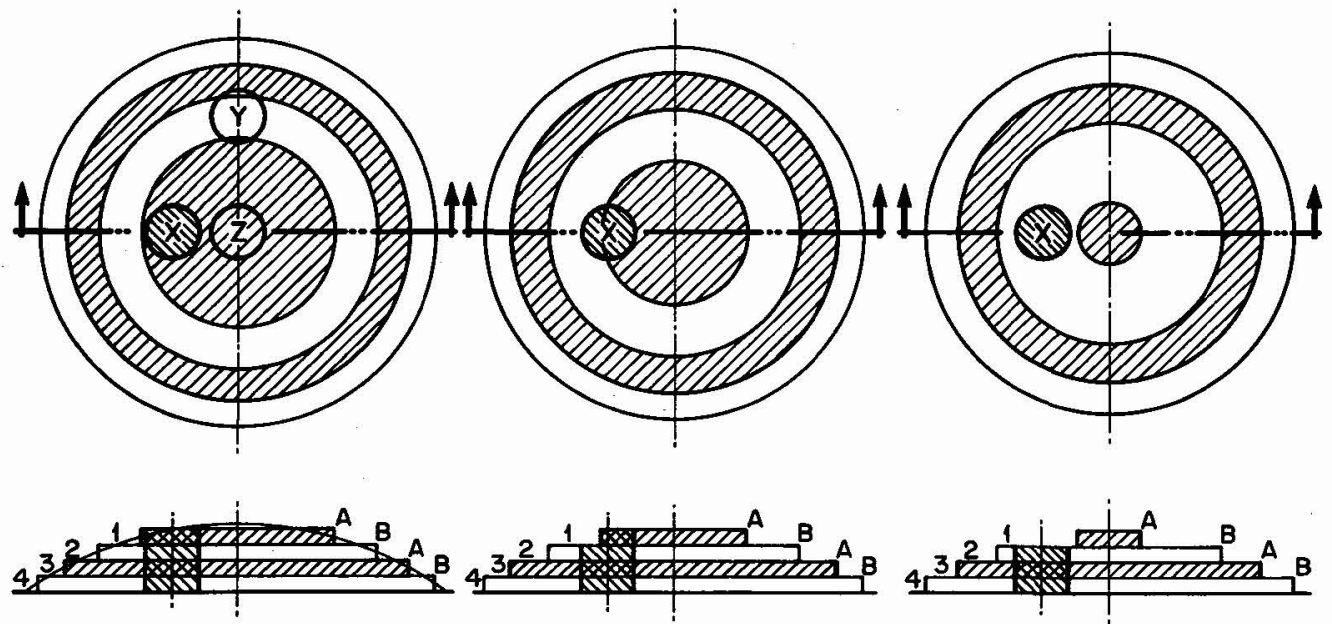

Fig. 1. Schematic diagram of the effective position of the probe aperture with respect to the pole. In position $X$, all atoms from layer 1 are collected before any atoms are collected from layer 2. Position $Y$ is not used as two layers are sampled simultaneously. Position $\mathrm{Z}$ is not used because of trajectory aberrations. 
The experimental conditions required in this type of analysis are more stringent than those normally demanded in atom probe composition determinations as shown in figure 2. In this ladder diagram a comparison is made between an analysis from a high index region and an analysis on a 001 pole using identical experimental conditions. In this type of diagram the arrival of each nickel atom is plotted as one horizontal step and the arrival of each aluminum as one vertical step. It is evident from the overall slope of the curve and from the number of atoms collected in both the mixed and the pure nickel layers that nickel atoms are being preferentially evaporated when the analysis is performed on the pole, whereas the analysis in the high index region produces a reliable composition. The facility to view the data as a ladder diagram during the experiment was found to be invaluable in selecting suitable experimental conditions [5]. The pulse fraction, standing voltage, and specimen temperature were selected to ensure that there was no preferential evaporation or retention of any element [7]. Preferential retention can be detected from the field-ion micrograph as shown in the 1\% hafnium alloy, figure 3. Preferential retention was also observed by the non-uniform evaporation or pinning of planes when inappropriate conditions were employed. It should also be noted that extremely slow evaporation rates $(0.1$ to 0.001 atoms per pulse) were found to be necessary to collect all atoms, especially at the end of plane where the instantaneous evaporation rate is much higher.

A short section of the atom probe data for each substitutional element is shown in figure 4. The position in the evaporation sequence of the substitutional elements is superimposed on these ladder diagrams. If the solute has a preference for the aluminum sites, which are only present in the mixed layers, then that element will be observed in the sections with the $45^{\circ}$ slope. This is the case for hafnium. When the substitutional element does not have a strong preference for either site then the element will be observed on both types of layers. This is the case for iron. If the substitutional element has a preference for the nickel sites then twice as much of the element will be found on the horizontal pure nickel layers as on the mixed layers. This is the case for cobalt. The site preference is calculated from the number of substitutional atoms detected on each type of plane taking into account the number of nickel and aluminum sites that are present in each plane and the alloy composition.

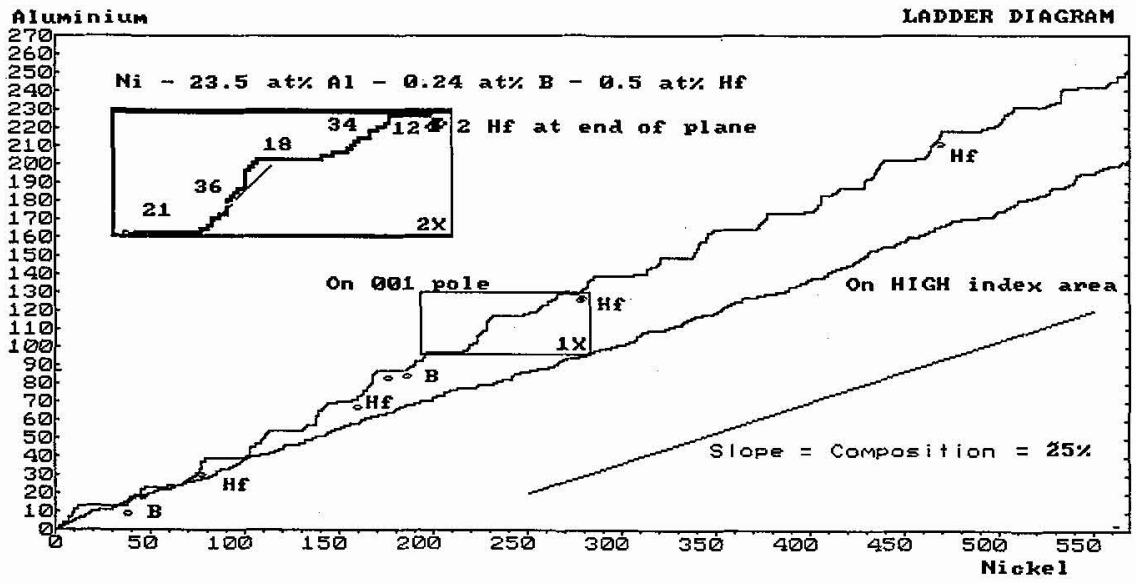

Fig. 2. Comparison of ladder diagrams of the $0.5 \%$ Hf alloy taken on the 001 pole and from a high index region under identical experimental conditions. The numbers in the insert indicate the difference in the number of atoms collected in each type of layer. Note the retention of $\mathrm{Hf}$ to the end of the layer. 


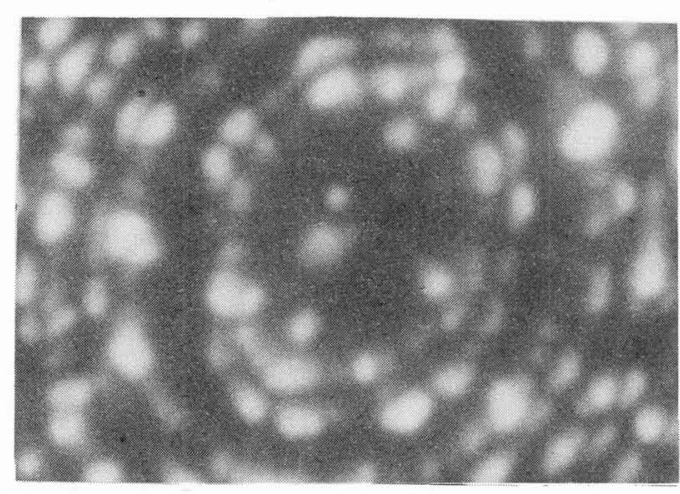

Fig. 3. Field-ion micrograph showing preferential retention on 001 pole.

Fig. 4. Ladder diagrams of the 001 planes in the $1 \% \mathrm{Hf}, 6 \% \mathrm{Fe}$ and $6 \% \mathrm{Co}$ alloys. The horizontal sections are the nickel layers and the sections with the $45^{\circ}$ slope are the mixed nickel plus aluminum layers. Arrows indicate position of substitutional elements.
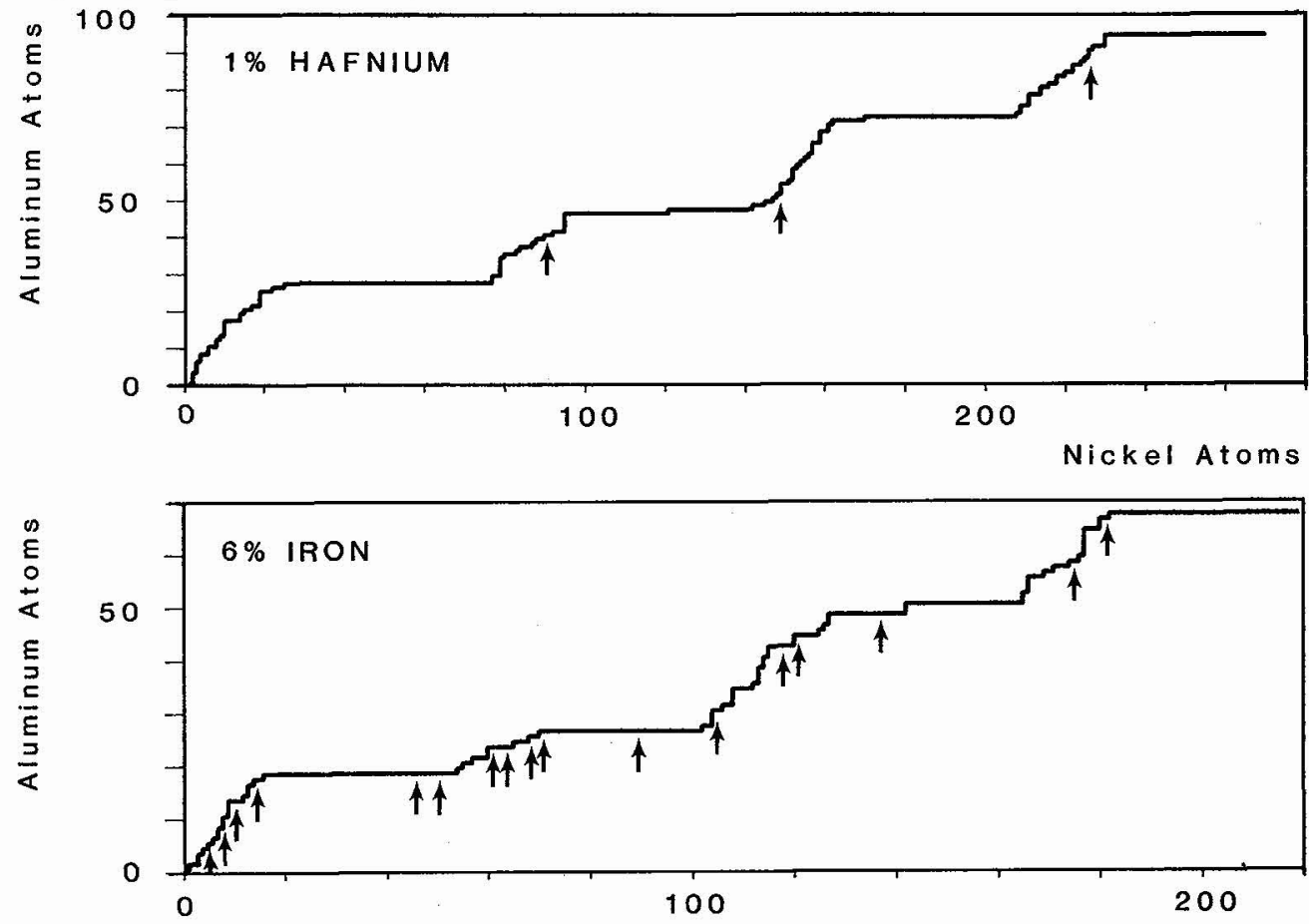

Nickel Atoms

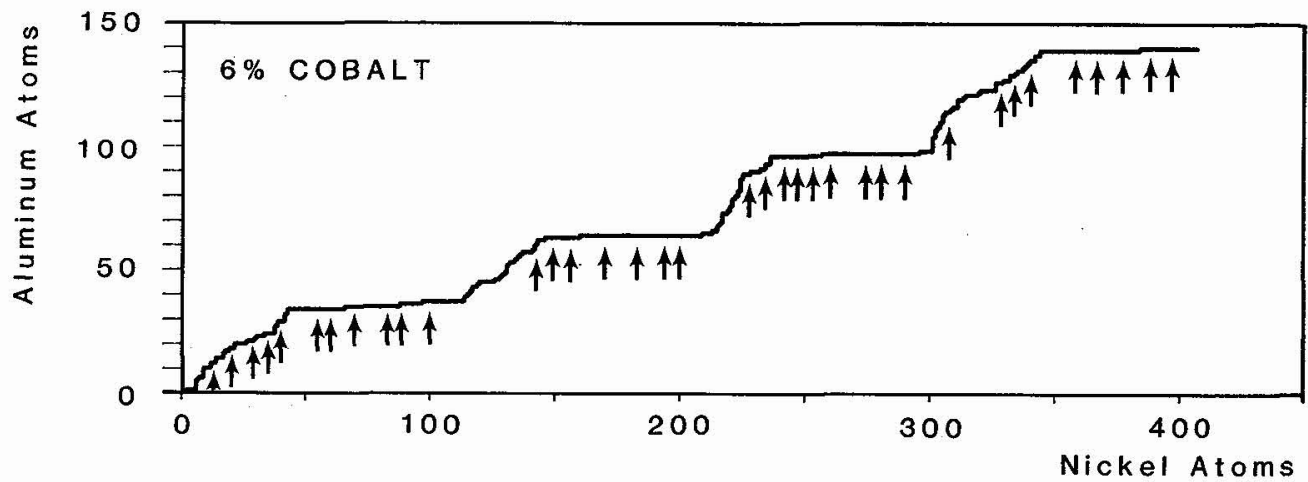




\section{ZONE AXIS ELECTRON CHANNELING MICROANALYSIS}

Electron channeling microanalysis is also complicated by the absence of any planes in the $\mathrm{L}_{1}$ structure containing only $\mathrm{B}$ atoms. However, certain zone axes, including

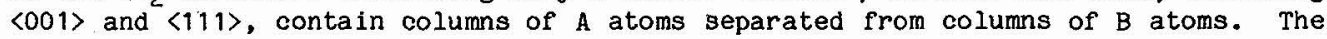
concentration; $C_{X}$, of element $X$ on the $B$ sites can be shown to be given by

$$
C_{X}=\{R(X / A)-1\} /\{R(B / A)-1\},
$$

where $R(X / A)=\left(N_{X} / N_{A}\right)^{z o n e} /\left(N_{X} / N_{A}\right)^{\text {random }}$, etc. and $N_{X}, N_{A}$, and $N_{B}$ are the characteristic $X$-ray intensities of elements $X, A$, and $B$. The procedure to determine the site occupation is therefore to record energy dispersive $X-r a y$ spectra at two orientations - an appropriate channeling zone axis and a "random" non-channeling condition.

An example of the zone axis electron channeling microanalysis is shown in figure 5 for the $3 \%$ hafnium alloy. The ratios of $\mathrm{HF} / \mathrm{Ni}$ and $\mathrm{Al} / \mathrm{Ni}$ were both observed to increase from the on-axis condition to the $1^{\circ}$ and $5^{\circ}$ deviations from zone axis indicating that hafnium follows the aluminum behavior. Unfortunately, corrections for ionization delocalization, which are normally ignored [2], were found to be necessary. The $A l_{K} / \mathrm{Ni}_{\mathrm{K}}$ ratios were corrected by comparisons with the $\mathrm{Ni}_{L} / \mathrm{Ni}_{\mathrm{K}}$ and the $\mathrm{Hf}_{\mathrm{M}} / \mathrm{HP}$ ratios which were found to change dramatically for small deviations from the zone axis, figure 5 .

\section{DISCUSSION}

The quantification of the results for all three substitutional elements from the two techniques is given in Table 2.
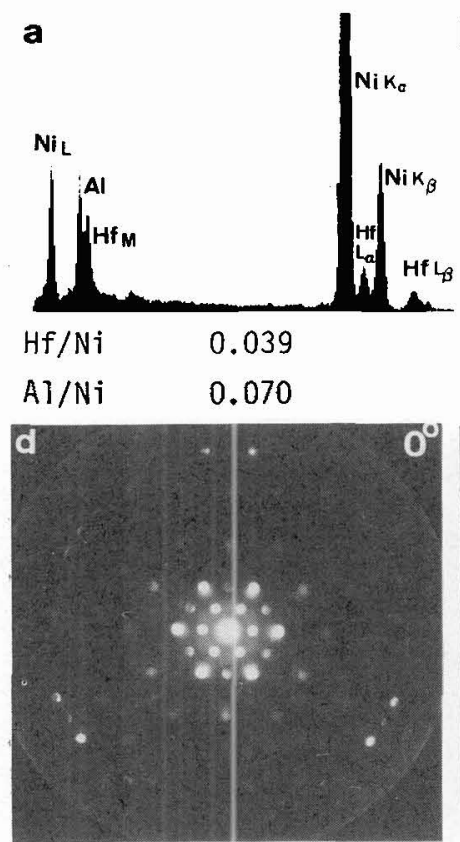

b

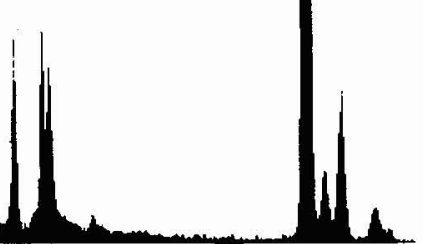

0.071

0.123

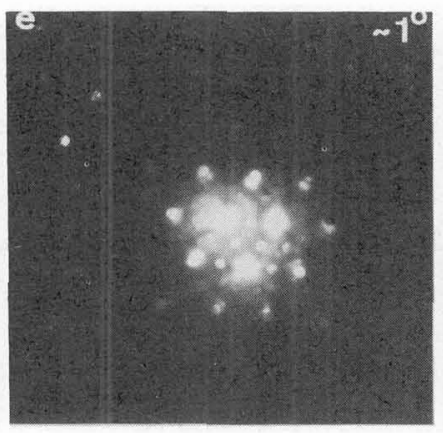

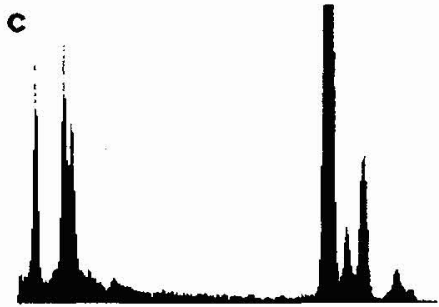

0.066

$(R=0.60)$

0.135

$(R=0.52)$

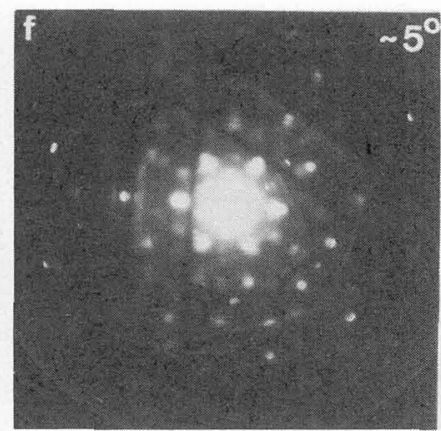

Fig. 5. Zone axis electron channeling microanalysis of the $3 \%$ Hf alloy taken near the 111 zone. ( $a, b$, and $c$ ) are energy dispersive $X-r$ ay spectra, at $100 \mathrm{kV}$, and ( $d, e$, and $f$ ) are the corresponding diffraction conditions. Note the change in intensities relative to $N I K_{B}$. 
Table 2. Site occupation of substitutional element on aluminum sites $(\%)$.

\begin{tabular}{|c|c|c|c|c|c|c|}
\hline Alloy & \multicolumn{2}{|c|}{ Atom Probe } & \multicolumn{4}{|c|}{ Electron Channeling Microanalysis } \\
\hline \multirow{6}{*}{$\begin{array}{l}0.5 \% \mathrm{HP} \\
1 \% \mathrm{Hf} \\
3 \% \mathrm{Hf} \\
6 \% \mathrm{Co} \\
6 \% \mathrm{Fe}\end{array}$} & \multirow{2}{*}{\multicolumn{2}{|c|}{100 pole }} & \multicolumn{2}{|c|}{ uncorrected } & \multicolumn{2}{|c|}{$\begin{array}{l}\text { corrected for } \\
\text { delocalization }\end{array}$} \\
\hline & & & $\langle 100\rangle$ & $\langle 111\rangle$ & $\langle 100\rangle$ & $\langle 111\rangle$ \\
\hline & $\begin{array}{l}76.9 \\
84.4\end{array}$ & $\begin{array}{l} \pm \quad 8.3 \\
\pm \quad 3.5\end{array}$ & \multicolumn{2}{|c|}{ - } & \multicolumn{2}{|c|}{ - } \\
\hline & & - & -127 & 84 & 87 & 114 \\
\hline & 0.5 & 0.5 & 36 & 10 & 16 & 17 \\
\hline & 42.6 & 3.3 & 229 & 34 & 51 & 48 \\
\hline
\end{tabular}

If the solute has no preference between the two types of sites in the perfect $\mathbf{L}_{2}$ $\left(A_{3} B\right)$ structure, then $25 \%$ of the substitutional element should be on the $B$ (aluminum) sites and the remainder on the A (nickel) sites. The zone axis electron channeling microanalysis results corrected for ionization delocalization effects and the atom probe results both indicate the same preference for all three elements; hafnium has a strong preference for the aluminum sites, cobalt has a strong preference for the nickel sites, and iron has a weak preference for the aluminum sites. In addition to the severe effects of ionization delocalization, the reliability of the channeling can be compromised by the presence of surface films, antisite defects, antiphase boundaries and dislocations. The atom probe results are not affected by these features. The small differences in magnitude between the APFIM and AEM results could be explained by such effects.

Both sets of results are in agreement with the site preference suggested by ochiai, Oya, and Suzuki [8], based on the direction of the solubility lobes in the ternary phase diagrams determined from the experimental data of Schramm [9], and Bradley [10]. This agreement would seem to suggest that the position of the solubility lobes is a reliable indication of site preference.

\section{CONCLUSIONS}

The results of these two techniques were in agreement for all the substitutional elements studied. The results indicated that, for the particular alloy compositions studied, hafnium has a strong preference for the aluminum sites, cobalt has a strong preference for the nickel sites, and iron has a weak preference for the aluminum sites. These results were also in agreement with the site preference suggested from the direction of the solubility lobes in experimentally determined ternary phase diagrams. This study has also indicated that care should be exercised in the correct implementation of these experimental techniques.

\section{Acknowledgments}

Research sponsored by the Division of Materials Sciences, U.S. Department of Energy, under contract DE-AC05-840R21400 with Martin Marietta Energy Systems, Inc. The authors would like to thank JiA. Horton for his assistance.

\section{REFERENCES}

[1] M.K. Miller and J.A. Horton, Soripta Met., 20, August (1986) in press

[2] J.Bentley, Proc. 44th EMSA, (1986) in press

[3] J.C.H. Spence and J.Tafto, J. Microscopy, 130, 147 (1983)

[4] C.T. Liu, "High Temperature Alloys: Theory and Design", ed. J.0. Stiegler, p. 289 , TMS-AIME, New York 1984

[5] M.K. Miller, J. de Physique, C2, 493 (1986); C2, 499 (1986)

[6] A.R. Waugh, E.D. Boyes, and M.J. Southon, Surf. Sci., 61, $109(1976)$

[7] M.K. Miller and G.D.W. Smith, J. Vac. Sci. Technol., 1 $\overline{9}, 57$ (1981)

[8] S. Ochiai, Y. Oya, and T. Suzuki, Acta Metall, $32,2 \overline{89}$ (1984)

[9] J. Schramm, Z. Metallk, 33, 403 (1941)

[10] A.J. Bradley, J.I.S.I., 163, 19 (1949); 168, 233 (1951); 171, 41 (1952) 